\title{
Teacher Training, Attitudes and Inclusion
}

\author{
${ }^{1}$ Fátima Coelho, ${ }^{1}$ Florentino Blázquez, ${ }^{2}$ Sixto Cubo \\ ${ }^{1}$ Universidade Fernando Pessoa, Portugal \\ ${ }^{2}$ Universidad da Extremadura, Espanha
}

\begin{abstract}
In this study we sought to discover teachers' attitudes toward the inclusion of students with special educational needs (SEN) in the classroom, and evaluate the factors suggested by them that would make an effective inclusion process possible. We also sought to understand the nature of the difficulties they experience in promoting inclusive education and to relate these to their training and professional development. We concluded that the variables of age, length of service, level of education and academic qualifications do not influence attitudes toward inclusion, . However, it was found that age significantly influenced the teachers' attitude variable, and specific training for working with students with SEN is more effective for younger teachers with shorter length of service With regard to the 'type of training' variable, we found that teachers whose initial training had included curriculum components related to SEN students did not develop more positive attitudes. In terms of continuing and specialist training, the data show that positive attitudes to inclusion are more frequent in teachers who have had continuing or specialist training in the SEN area as part of their professional development. Respondents also highlighted six categories of difficulties in the implementation of inclusion in schools: the attitudes of teachers; the attitudes of families; coordination between educational staff; the attitude of the teaching community; lack of human and physical resources; and lack of training to work with SEN students.
\end{abstract}

\section{Introduction}

The concept of the inclusive school requires a radical change in the whole teaching system. Current trends focus this change essentially on school, on stakeholders and of course on teachers as the key players in an educational establishment. However, for this to happen it is essential that teachers' attitudes towards inclusion are positive, because it isthey who have influence in the education and learning process of the students. Positive attitudes reinforce success and are the foundation for inclusion [1].

Some researchers, like Avramidis and Norwich [2] consider that the factors that influence teachers' attitudes towards inclusion are personal: age, gender, academic qualifications, type of training, length of service, special education experience, or related to the context; that is, kind of teacher, employment status, educational level, number of students in class, work experience and school location [3] .

Other studies also point to a very strong relationship between teachers' attitudes and their training. These different explanations for the relationship between attitudes and inclusion led us to ascertain the most important factors influencing teachers' attitudes in Portugal; whether personal ones related to training or contextual more system-related and educational policies. A previous study carried out by the author, with a sample of 135 teachers, points to a strong relationship between education and attitudes towards inclusion, with the other factors not being relevant.

In the light of this and based on the theoretical references underlying the literature review, the following general objectives were formulated for the study: to identify the attitudes of basic education teachers, with regard to inclusion of students with special educational needs (SEN) in the classroom,and evaluate the factors suggested by them that would make an effective inclusion process possible. We also sought to understand the nature of the difficulties that teachers feel in promoting inclusive education and relate them to the kinds of attitudes that they demonstrate towards their career and training needs.

\section{Theoretical context}

In future, a school will have to be as good as its staff. This envisages the importance given to the training of teachers throughout their professional career. Today we know that education is a continuous, systematic and organised process that lasts as long as a teacher's career. For this reason, the emphasis today is on an ecological approach to teacher training. Various writers support the idea that teacher training today cannot simply be reduced to imparting technical and instrumental knowledge, since affective and cognitive aspects play a key role. Initial teacher education comes into the debate in that it provides the foundations for the construction of a teacher profile required in every school system including key aspects such as learning how to teach, professional socialization and the ability to mediate [4].

In Portuguese society there has been a clear lag over the years between policy objectives on teacher 
training and practice. Any teacher is a teacher of "someone" teaching "something" in a certain context and for certain purposes; it is important to place training and teaching professionalism in a given political, social, cultural and economic context.

A new training concept has emerged- the idea of lifelong learning- linked to the professional development of teachers which emphasizes evolution and continuity, where theory and practice should be considered in an interconnected way. [This principle assumes that teachers must have training in order to be able to think about their practice, implying that each school situation is different and therefore the needs and responses to those needs are different. Reflective training processes are a strong reference point for many studies and proposals in the field of teacher education [5].From this socially constructed conception of knowledge, we understand what is expected from the reflective practical teacher and its importance in the scenario of the inclusive school.

The concept of inclusion that gave rise to the inclusive school or school for all, and inclusive education [6], profoundly changed traditional practices, replacing them with a more global concept, in which every student has the right to an education without exclusions. Inclusion implies a conceptual framework and consists of six components: i) All pupils should be educated in the schools near to where they live; ii) the percentage of pupils with SEN in each school/class must be representative of their prevalence; iii) schools should be governed by the principle of "zero" rejection; iv) pupils with SEN should be educated in regular schools, in environments appropriate to their age and educational level; v) education in cooperation and peer tutoring are preferred teaching methods; vi) the support given by special education services should not exclude pupils with SEN [7]. Including SEN students in the classroom will build in the opportunity for access to quality education, whether for them or for their classmates who don't have these challenges. Defence of this principle is based on the assumption that heterogeneity and diversity are values and not obstacles. It may even become the driver for a new generation which is fairer, truer and more supportive. An inclusive school is therefore an institution that will enhance the multiple expression of cultures to be found in each one; it is an intercultural school, building mutual recognition and preparing the foundations for a critical interpretation of the world

[8]. . The attitude and professional development of teachers also depend on the stage they are at in their career, with the most experienced teachers tending to show more resistance to change Several writers assume that the development of practices and the construction of more inclusive educational settings in mainstream schools are closely related to teachers' and other educational officials' attitudes in relation to inclusive education [9],

Teachers' attitudes, which some studies have linked to their pedagogical ideas, training and experience, appear to be decisive for the possibilities and limits of inclusion. Teachers with more positive attitudes more easily change and adapt their work in order to benefit students with special needs, while positively influencing their peers [10] [11], because a teacher with a higher educational level is more likely to accept methodological changes and attitudes. We know that attitudes towards people with disabilities are negative and are based on lack of experience or information. Since attitudes are multidimensional and may be influenced by the type and degree of disability, they cannot be considered in such a simplistic way. It is necessary to explain the context, the purpose and basis of these beliefs. In order to accept this idea, it would be necessary to identify the kind of information and experience that is associated with certain attitudes. One important belief is that experience with people with special needs can be associated with more positive attitudes. Anybody who works with disabled people has more favourable beliefs and attitudes towards them and teachers themselves differ in their attitudes and beliefs towards this sector of the population. For a special needs teacher the presence of a student with these challenges may mean more work, and for a class teacher it may mean complications.

\section{Methodology and procedures}

The study presented here is descriptive in design, and is intended to describe some aspects, facts or phenomena of a particular situation. The information was collected using three distinct processes (questionnaires, focus groups and document analysis). The mixed-type questionnaire used contains an attitudinal scale towards disability (AFI), whose reliability analysis has a Cronbach alpha of 0.831 . The analysis was supported on normality tests (K-S), randomness (Rachas) and the principle of homogeneity (Levene). Where any of these assumptions failed, non-parametric tests were used. To broaden this study, two more data collections were made, through two focus groups with eight members each, based on various models [12], [13]. For document analysis, 23 teachers' texts were used. The focus groups, as well as all the documents, were subject to content analysis, using computer support.

\subsection{Target}

The sample consists of 325 teachers from schools in different regions of Portugal. $46.2 \%$ are classroom teachers, while $30.2 \%$ are from the area of special education. Of the respondents $91.7 \%$ are graduates. About half of teachers have between 7 and 25 years 
of professional experience. It should also be noted that $22.5 \%$ have been teaching for less than three years. We found that $43.4 \%$ of teachers covered working with students with special educational needs in their initial training and that $25.5 \%$ of them consider that this training was insufficient. $50.5 \%$ of the participants have some continuous teacher training in this area. This also does not meet teachers' expectations; in $39.3 \%$ of cases they consider the training insufficient in terms of quality. As regards specialized training on the subject, $38.7 \%$ of respondents had received such training, specifically directed to disruptions in the cognitive and motor domain.

\section{Discussion}

Although other variables in the study were used, we will focus only on the following: training and information received, teacher type, degree, regular teaching, teachers' attitude and special education, with regard to the inclusion of children with SEN in the classroom.

We conclude that a degree does not influence attitudes towards inclusion (Kruskal-Wallis $\mathrm{H}$ 0.941). Other researchers [9], in contrast, suggest that teachers with higher academic qualifications theoretically manifest more positive attitudes, but they have fewer ideas and goals for working with students with SEN, when compared with other teachers with lower academic qualifications. With regard to the training variable, we found contrary to expectations that teachers who did not have input on students with special educational needs in their initial training course had more positive attitudes than those who did. However, the difference is minimal, and in generally positive attitudes are above average.

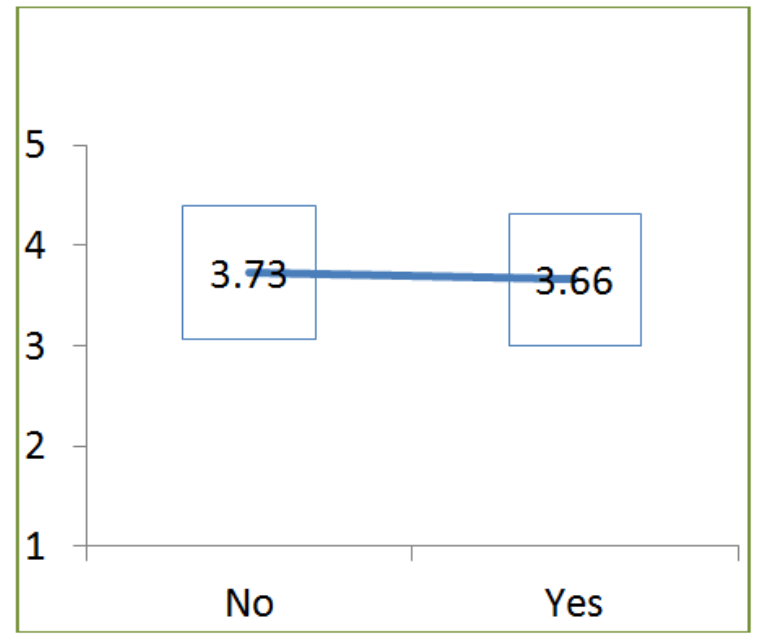

Figure 1. Scale of attitudes on inclusion by initial training received
To determine if the difference is statistically significant we used the Mann - Whitney $U$ test and the $\mathrm{p}$ value $=0.092$ shows us that there are no significant differences, so we conclude that the initial training does not determine the type of teacher attitudes towards the inclusion of pupils with SEN in the classroom. The same conclusions were reached by Gafoor and Asaraf [14], who state that there were no significant differences with regard to the attitudes of teachers and their initial training, perhaps because this concept is already internalized by the individual. Other studies show a relationship between positive attitudes and curricula where there are subjects related to [15].

Coincident with the hypothesis (continuing education within special education needs develops the most positive attitudes in teachers towards the inclusion of pupils with SEN in the classroom) these are the results from figure 2 where we can see, there is an increase in positive attitudes towards students with SEN after the teachers have received training.

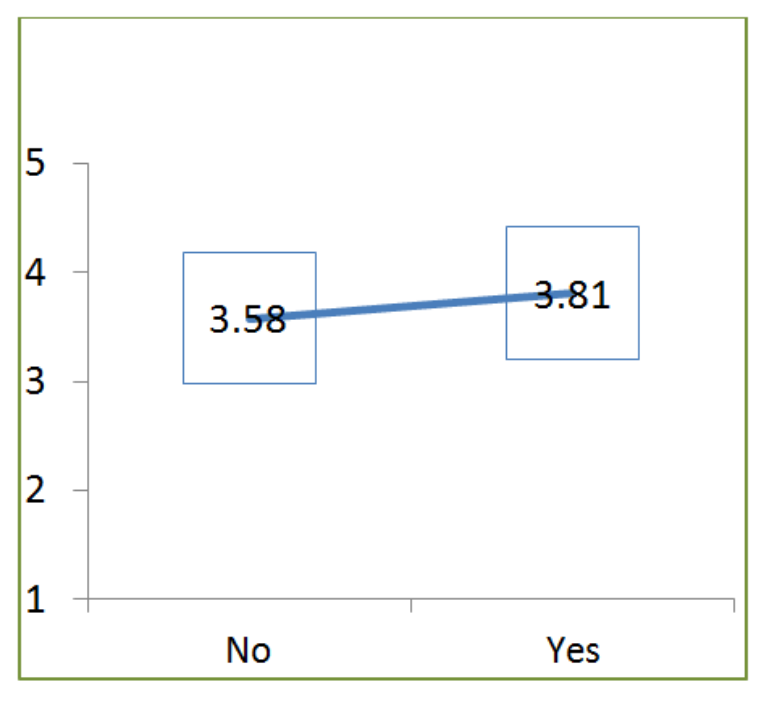

Figure 2. Scale of attitudes on inclusion by continuous training received

There is a clear increase in positive attitudes towards students with SEN after the teachers have received training. The differences found in the $U$ Mann-Whitney test $(\mathrm{p}=0.00)$ confirm this hypothesis, so that it seems beyond doubt that continuous training influences the attitudes of teachers towards the inclusion of pupils with special educational needs in a positive way. Several studies confirm these results, indicating that this influence is greater than the experience [6], [16], while increasing the self-esteem and self-confidence of teachers and skills capacities for professional practice.

It appears therefore that neither initial training nor daily experience prepare teachers for inclusive practices, shared reflective practice and the concept 
of continuing education, which can determine more inclusive attitudes [16].Regarding specialized training, it also influences the attitudes of teachers.

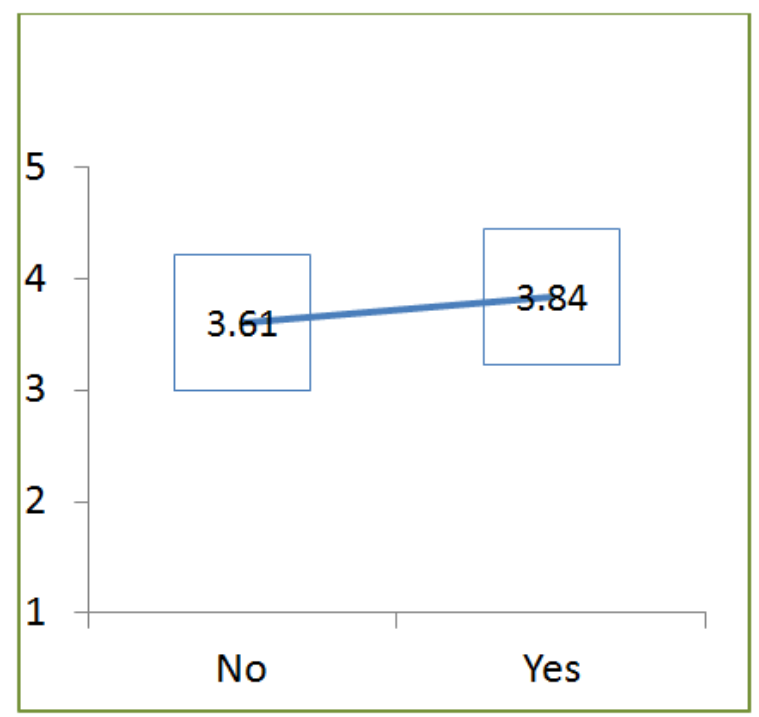

Figure 3. Scale of attitudes on inclusion by specialized training received

Applying the Mann-Whitney $U$ test $p$-value = 0.00 means that the differences found in the above graph are significant. In common with other researchers we found that training in special education compared to normal training promotes more positive attitudes [17].

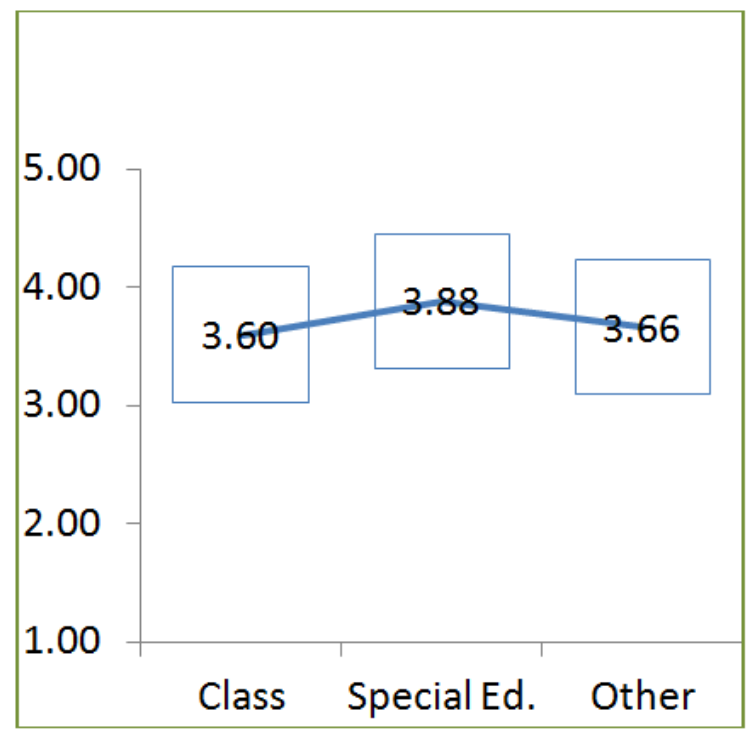

Figure 4. Scale of attitudes on inclusion by type of teacher role in school

Another variable studied was the kind of role the teacher plays in school (special education teacher / regular teacher and head teacher) which positively influences the attitudes of primary school teachers towards the inclusion of pupils with SEN in the classroom).

The study shows, that special education teachers have more positive attitudes towards pupils with special educational needs. To confirm the statistical significance, we applied the nonparametric KruskalWallis $\mathrm{H} \quad(\mathrm{p}=0.00)$. We accept that there are significant differences between the groups and therefore attitudes change depending on the role the teacher plays. In this case we proved post-hoc that it is teachers with special education functions who show more positive attitudes towards pupils with special educational needs.

One researcher also concludes that there is a relationship between the teacher's situation at school and attitudes towards inclusion, and teachers with more stability, who have security of tenure, are less inclusive. She also found that teachers of educational guidance departments, and teachers linked to the arts have more inclusive attitudes, contrary to regular teachers or those from other departments [18].

To collect the opinions of teachers about the factors that facilitate inclusion we asked them in the last part of the questionnaire to classify in descending order, from the most important to least important, the conditions they consider more conducive to the process of inclusion of SEN pupils in the classroom ("teachers' attitudes"; "specialized teachers"; "specific training"; "teaching methods"; "evaluation/monitoring of students"; "collaboration between teachers" and "materials and resources").

We also sought to discover whether the degree of importance attributed by teachers to the type of factors that would make an effective inclusion process possible is influenced by personal and professional factors.

We conclude that the most important condition chosen by the teachers is "teachers' attitudes," followed by "specific training". It should also be noted that there are degrees of importance assigned by teachers to personal and professional factors. Overall we can point out that teachers aged between 31 and 40 are those who most value the inclusion process. It appears also that as age increases, the relevance attributed to teachers' attitudes increases, while the younger teachers value materials and resources more. Finally, the importance given to specific training is influenced by age; that is, teachers who are between 31 to 40 and 41 to 50 value this condition more. Studies done by Huberman [19], show that teachers' attitude and performance changes throughout their career, while others claim teachers that have more experience verbalize more their lack of knowledge in the field of SEN.

As for the influence of educational and professional qualifications, cited by teachers as necessary to be able to carry out an effective process of inclusion, it was found that the importance given 
to specific training requirements for working students with SEN is significantly higher in licensed teachers.

There is a pronounced rise in specific training in licensed teachers, who in turn devalue the condition "Collaboration between teachers". Regarding qualifications and on reviewing some studies [6], [16], we conclude that the professional qualifications to which specific training is associated should be taken into account in the implementation of an inclusive school, given the strong relationship this has to teacher attitudes. Regarding the training variable, we analyzed the influence of initial, continuous or specialized training in the importance given to each of the conditions for an effective inclusion process. With regard to the training variable, we sought to find out if including input on students with special educational needs in initial training influences the degree of importance attributed by teachers to the factors for making an effective inclusion process possible. In this case there is parity between the factors, as three of them improve choices when related to initial training that includes input on SEN students and three worsen the degree of importance attributed. 'Teachers' attitudes' are important, as people who have had input relating to students with special educational needs in initial training do not value this factor.

Although there were some differences between the two groups (teachers who had SEN in their initial training courses and those who did not), these differences were not statistically significant.

After relating all factors associated with this variable, it appears that there is no influence on participants' choices.

Some researchers argue that teachers must have an inclusive education module in their initial training, because they will feel more comfortable with inclusive practices [20]. Others, however, arguethat there should be a more systematic introduction of intensive training [21]. With regard to continuous or specialized training in terms of special needs education influencing the degree of importance attributed by teachers to the factors for making an effective inclusion process possible, it can be concluded that the teachers involved in the study who attended this type of training attributed greater importance to 'teachers' attitudes' and that this is higher for those who had specialized training.

The type of role that the teacher plays in school (special education teacher/regular teacher and teacher with management responsibility) influences the degree of importance given by teachers to the factors for making an effective inclusion process possible.

The trend of the data shows that special education teachers are different from the others in the importance attributed to 'teachers' attitudes'. They consider it the most important factor in implementing an effective inclusion process. On the other hand, they attach less importance to 'specific training' than the rest of their colleagues. They do not consider 'specialized teachers' or 'materials and resources' very important. The latter factors are more relevant to the class teachers without specific training.

Within this research project another concern, besides measuring the attitudes of teachers, was to investigate the process that would be needed for a school to become more inclusive. To understand this process it was also important to monitor the difficulties experienced by teachers, using data obtained from the documentary collection and the conclusions from focus groups. In general, teachers gave as an explanation for the difficulties encountered in the implementation of an inclusive school. There were two types of factors. The first were based on causes of a contextual nature, such as the low participation of families and the attitudes of the educational community. Thus $31 \%$ of teachers refer to the family, stressing the importance of its involvement in the educational process of SEN students. They state that the active participation of parents is essential in enabling them to develop joint efforts between family and school community, so that teachers may collect inside information that can significantly contribute to the better diagnosis and assessment of the special needs of each case/student.

Another factor referred to is the 'dynamics of the educational community', which covers a range of different structural sub-factors. Of those surveyed $20 \%$ attach importance to the awareness and acceptance of these SEN students by institutional agents, such as the school headteachers and other school governing bodies/ministry of education and the teachers themselves. $22 \%$ of respondents also stress the importance of structural factors independent of the will of teachers, such as the criteria for selection and teaching of classes, so that there were fewer students per class which allowed more individualized follow-up. To this factor $16 \%$ of respondents add the idea that there must be interaction between the educational community and the local community.

Studies done by Rodríguez Tejada [18] and also reach these conclusions.

With regard to causes of a personal nature these were related to attitudes; lack of training that did not allow them for example, to know how to build or adapt various specific materials, the impossibility of programming content management in heterogeneous classes, many difficulties in time management; cooperation in team work among others. Participants also indicated the individual profile of each teacher as the main problem, as well as the anxiety of not fulfilling their duties.

Similar issues were found by other researchers in their studies and state that teachers attribute the greatest difficulties for the promotion of an inclusive 
school to issues regarding themselves [1], [22]. However, others argue that the most important is our will to change the school [1], [23].

All respondents who said they had no specific training to work with students with special educational needs, attribute the inclusion problem to teacher training. Thus, regular education teachers seem to need to know more about students to adapt their working and teaching methods to be able to define new strategies to support pupils with SEN [18], [23].

To find a response for to the second general research objective (to ascertain the nature of the difficulties that teachers feel in promoting inclusive education and to relate them to the kind of attitudes demonstrated, with their course and training needs), and note the main difficulties elementary school teachers face on a daily basis in being able to be encourage inclusive education, we also asked participants about the most frequent difficulties they had in their teaching practice. 202 teachers responded to this question

The different responses were again grouped into two types of factors: personal and contextual. In terms of personal factors three categories stand out: teachers' attitudes, training and time management.

In teachers' attitudes category, $14 \%$ of respondents state that in their daily teaching practice the attitude of some of their colleagues does not favour their work, and many of them are not very receptive to the inclusion of students in regular education.

In the training category, the most commonly referred to by teachers, $38 \%$ of respondents reported that the contact with SEN students, whether on a relational level or in planning lessons, revealed some weaknesses on the part of teachers in terms of training, which greatly complicates how they perceive their job.

In the time management category, there is a conviction among 7\% of teachers that their work is also very much constrained by lack of time, which does not allow them to better manage the lesson plan and develop a more personalised service with these students.

In terms of contextual factors, the 'others' attitudes' category contains two sub-categories: family and educational community, and the 'external constraints' category includes the sub-categories human resources and material resources.

With regard to the sub-category 'family' $3 \%$ of teachers are convinced that the attitude of their own families is not favourable to working together for the benefit of students. While, on the one hand, there are families who do not engage actively in the schooling of their children, others pressure and often make demands on teachers beyond what is professionally required of them. Reference is also made to the need for support at a social, psychological and even financial level for these families.

In the subcategory 'educational community', teachers refer to the issue of the relationship between educational stakeholders, and feel the need for a coordination between all of them including the external involvement of the family. Of those surveyed $15 \%$ highlight the importance of teamwork so that executive bodies, teachers and other educational staff (psychologists, speech therapists, etc.) combine their efforts, knowledge and attributes with each other in order to better define the strategies for including these students in regular education.

The less receptive attitude of the educational community, in addition to teachers, as we have seen, can be an obstacle to the success of the strategies pursued to include these students.

With regard to external constraints and human and material resources, $9 \%$ of teachers believe that example of difficulties at organizational and structural level include the design of the class (high student numbers), the rigidity of timetables, curriculum design and lack of support from the Ministry of Education itself.

As regards human and material resources, two other difficulties may be considered external factors, but we decided to categorise them independently due to the frequency with which they were mentioned. The lack of both human resources and teaching materials makes the work difficult for $14 \%$ of teachers.

On the one hand, the frequent absence of other skilled personnel such as psychologists, speech therapists, etc., does not allow them to use and develop strategies together with other professionals; on the other hand, the shortage of teaching materials does not allow them to develop activities which are pedagogically more appropriate for these students.

These constraints therefore affect the task of defining and adapting appropriate teaching strategies. They have difficulty in designing activities for students with SEN as well as adapting the curriculum strategically to develop their potential to the maximum, not only due to the lack of training already mentioned but also the lack of resources:

We also asked teachers for their opinion on what content/input should be included in the curricula of teacher training schools so that they could effectively meet the needs of all students.

The analysis allows us to respond to specific objectives: making an inventory of the training needs of teachers in this area and drawing up proposals for curricular content to be included in initial and continuing teacher education programmes. We wanted to identify teachers' most pressing training needs.

Teachers mention that have a need for training at various levels, in particular regarding the description of the different types of disabilities, so that teachers 
can create working methods; ideas on assessment and intervention in SEN; training on special education itself and regulatory legislation

Of the teachers surveyed, $40 \%$ feel they need to have input/content related to SEN in their initial training, while $30 \%$ of respondents believe that in order to effectively meet all students' needs, including SEN students, they needed to have content related to special education in their initial training, especially in terms of educational assessment; intervention methodologies; curricular and pedagogical differentiation and intervention strategies. In the opinion of $30 \%$ of teachers, their study plans should include input which provides them with the tools to work and effectively meet the needs of all students, especially those with SEN. They mention one relevant aspect to do with more practical matters, an internship in the field of special education, in order to become more familiar with this issue.

The input they mention is based on the need to know more about SEN; teaching techniques (students, staff and family); teaching methods; ethics; pedagogical differentiation; legislation, among others.

These are issues that some writers also refer to as important in teacher training [8] [14]

\section{Conclusion}

Regarding initial training, we conclude that teachers who had covered SEN students in their training courses did not develop more positive attitudes. However, teachers who had continuous training or specialized training during their career have more positive attitudes compared with those who did not have this type of training. It was also found that the specialized training within the SEN framework significantly influences the relevance given to teacher attitudes towards encouraging inclusion.

The type of role the teacher plays in school influences positive attitudes towards inclusion because the data shows that a teacher who carries out special education functions has more positive attitudes than classroom teachers or those with management responsibilities. Thus, special education teachers consider attitudes as the most important condition, while teachers with other functions give greater importance to the existence of specialized teachers in schools.

We also point to six categories of problems signaled by teachers that are described below: teachers' attitudes as a barrier to inclusion; families attitudes such as low parental involvement in the educational process of their children; communication between educational providers; the attitude of the teaching community; lack of human and physical resources and lack of training to work with SEN students. In relation to training needs, difficulties were found both in terms of the pedagogical relationship, lesson planning, design of activities, curriculum changes, time management and classroom management skills.

Within the deficiencies mentioned by the teachers in promoting inclusive schools, the one mentioned most frequently was the need for training. As regards initial training, they mentioned modules which included content related to legislation on SEN, approaches to different types of disability, concepts of assessment, specific educational intervention and educational differentiation methodologies, cooperative learning, classroom management and curriculum organization. All refer to the relevance of in-service training.

On completion of this work, and after a thorough reflection on the entire progress of this research, we would argue for its importance in understanding the issues around teacher attitudes towards the inclusion of pupils with SEN. This also allows us to conclude that inclusive attitudes are today, from the philosophical point of view, a reality accepted by the majority of teachers, who argue that the heterogeneity of a class provides richer learning situations.Taking into account the nature of this research and the background to it, in addition to the results and conclusions obtained, we aim to set out guidelines for future use, and offer some recommendations both for teacher training and for further research.

Teacher training takes educational practice and teaching as the object of analysis. It enables teachers to understand the relationships between society and knowledge gained and helps them to see research as a way of learning, taking into account the individual, the collective, the institution, the community, the underlying and implicit fundamentals, the decisions and attitudes of the teacher in an inclusive context, the school, the classroom and the whole school community.

The aim is to develop training which seamlessly integrates initial teacher education, induction and continuing professional development throughout a teacher's career, which has educational practice and teaching as its focus and which helps teachers to see research as a way of learning, through learning opportunities in different areas: formal (approved by the Ministry of Education), informal (during meetings) and non-formal (which does not follow an institutional plan).

With regard to initial teacher training we think that higher education institutions have an important role to play in developing effective partnerships with schools and other stakeholders in order to ensure that teacher training courses are based on solid evidence and good teaching practices; which encourage selfreflection, in order to value the concepts and previous ideas of future teachers about the profession 
and the school, and about what teaching and learning is when it takes diversity into account; that learning is carried out in the context of professional performance. The emphasis on initiation into professional practice, and in particular in teaching practice supervised by qualified teachers, in order to recognise that this is a privileged and irreplaceable moment in acquiring the skills to act as a professional.

We emphasize that initiation into professional practice should be undertaken in stages, from the start of initial training, not as a component that is disconnected from the others, but as a period for mobilising and combining a diverse range of knowledge in solving concrete situations in the classroom, in the school, and in relationships with the community, based on an inclusive school.

In addition to organising practical training initiatives in the classroom which are progressively more intense, longer and of greater responsibility over the duration of the course, there should also be a mandatory internship component in inclusive classrooms in order to learn how to deal with SEN students. The selection of tutors and supervisors should be based on their practical experience of dealing with SEN students in order to develop the skills of cooperative working in prospective teachers, based on continuing reflection in the context of an inclusive school.

Finally we have suggested a research approach to changing community attitudes to be reflected in the inclusive school and conversely to find out about the influence of the external environmental and the changes induced in and by the inclusive school.

\section{References}

[1] Marchesi, A., A prática das escolas inclusivas. Em D. Rodrigues (Ed.), Educação e diferença: valores e práticas para uma educação inclusiva, Porto Editora, Porto, 2001

[2] Avramidis, E., and Norwich, B., Teachers' attitudes towards integration/inclusion: A review of the literature. European Journal of Special Needs Education, 17(2), 2002, pp.129-147.

[3] Loreman, T., Earle, C., Sharma, U. and Forlin, C. (2007). The development of an instrument for measuring pre-service teachers' sentiments, attitudes, and concerns about inclusive education. International Journal of Special Education, 22(2), 2007, pp. 150-159.

[4] Formosinho, J. (Coord)., Formação de Professores. Aprendizagem profissional e acção docente. Porto Editora, Porto, 2009.

[5] Roldão, M. C., Diferenciação curricular e inclusão. Em David Rodrigues (Org.). Perspectivas sobre a inclusão. Da educação à sociedade. Porto Editora, Porto, 2003..
[6] Rodrigues, D., Paradigma da educação inclusiva Reflexão sobre uma agenda possível. Inclusão, 1, 2000. pp.7-13.

[7] Morgado, J., Qualidade, inclusão e diferenciação pedagógica: importância e dificuldade atribuída por professores do $1^{o}$ ciclo. Braga, Universidade do Minho, 2001.

[8] Ainscow, M., From special education to effective schools for all: a review of progress so far. Lani, F. (Ed.).In The Handbook of Special Education. Sage London, 2006.

[9] Sharma, U., Forlin, C., Loreman, T. and Earle, C., Preservice teachers attitudes, concerns and sentiments about inclusive education. An international comparison of the novice pre-service teacher. International Journal of Special Education, 21(2), (2006), p. 80-93.

[10] Forlin, C., Inclusion: Identifying potential stressors for regular class teachers. Educational Research, 43, 2001, p. 235-245.

[11] Sharma, U., Forlin, C. and Loreman, T., Impact of training on pre-service teachers' attitudes and concerns about inclusive education and sentiments about persons with disabilities. Disability \& Society, 23, 2008, p.773785 .

[12] Simon, J., How to conduct focus group. Nonprofit World, 17(5), 1999,pp. 40-43

[13] Cubo, S. D., Análisis de contenido. In Cubo, S. D., Martín, B. M. \& Ramos, J. L. S. (Coords.). Métodos de investigación y análisis de datos en ciências sociales y de la salud. Ediciones Pirámide, Madrid, 2008.

[14] Gafoor, A. and Asaraf, M., Inclusive education does the regular teacher education programme make difference in knowledge and attitudes? International Conference on 'Education, Research and Innovation for Inclusive Societies India, Dravidian University, Kuppam, Andhra Pradesh, 2009, p. 19-21

[15] Loreman, T., Sharma, U., Forlin, C., and Earle, C. Pre-service teachers attitudes and concerns regarding inclusive education. Paper presented in International Special Education Conference (ISEC), Glasgow, United Kingdom, 2005.

[16] Kuyini, A. B. and Mangope, B., Student teachers' attitudes and concerns about inclusive education in Ghana and Botswana. International Journal of Whole Schooling. 7(1), 2011.pp. 20-37.

[17] Mastin, D., General and special education teachers' attitudes toward inclusion of down syndrome students, Proquest, UMI, EUA, 2010.

[18] Rodríguez Tejada, R., La Atención a la Diversidad en la ESO. Actitudes del Profesorado y Necesidades Educativas Especiales, Diputación de Badajoz, Badajoz, 2006. 
[19] Huberman A. M., O ciclo de vida profissional dos professores. In A. Nóvoa (Org.), Vidas de professores Porto Editora, Porto, 2000, pp.35-62.

[20] Gilmore, L., Campbell, J. and Cuskelly, M., Developmental expectations, personality stereotypes, and attitudes towards inclusive education: community and teacher views of down syndrome. International Journal of Disability, Development and Education, 50(1),2003, pp. 65-76.

[21] Cook, B. G., A comparison of teachers' attitudes toward their included students with mild and severe disabilities. The Journal of Special Education, 34(4), 2002, pp. 203-213.

[22] Parker, S., A comparison of the attitudes of secondary regular and special education teachers toward inclusion of students with disabilities in their classrooms, Regent University, Virginia, 2009.

[23] Morgado, J., Qualidade na Educação - Um desafio para os professores. Editorial Presença, Lisboa, 2004. 